Л.Н. Сернов,
Е.А. Левкова
Коррекция ишемических-реперфузионных повреждений сетчатки у крыс с использованием агонистов имидазолиновых рецепторов I, II типов

Общество с ограниченной ответственностью «Фармконсалтинг», ул. Кирова, д. 19, г. Старая Купавна, 142450, Российская Федерация Автор для переписки: E.A. Левкова (last_81@mail.ru)

\begin{abstract}
Аннотация
Актуальность: В литературных источниках отмечено отсутствие средств для направленной, специфической коррекции ишемии сетчатки, в связи с чем, актуальным явилось изучение возможностей фармакологической коррекции ишемических - реперфузионных повреждений сетчатки в эксперименте. Цель исследования: Повышение эффективности фармакологической коррекции ишемических реперфузионных повреждений сетчатки с применением агонистов имидазолиновых рецепторов I, II типов. Материалы и методы: Оценку протективных свойств агонистов имидазолиновых рецепторов на модели ишемииреперфузии сетчатки у крыс линии Wistar с использованием субстанции С7070 (3-(1Н-бензимидазол-2-ил)-1,2,2-триметилциклопентанкарбоновой кислоты) в дозах 10 мг/кг и 50 мг/кг и калиевой соли С7070 в дозе 10 мг/кг проводили по динамике морфометрических показателей толщины слоев сетчатки. Результаты: На модели ишемии-реперфузии сетчатки показано, что калиевая соль С7070 обладает более выраженным ретинопротективным действием, чем C7070. На фоне коррекции С7070 в дозе 10 мг/кг толщина фоторецепторного слоя больше на $10,9 \%$ ( $>0,05)$ по сравнению со значением в группе с моделью патологии и достоверно не отличается от него; толщина внутреннего ядерного слоя на 21,6\% больше, чем в группе с моделью $(\mathrm{p}<0,05)$; толщина ганглионарного слоя и нервных волокон достоверно не отличается от значения в группе с моделью патологии. На фоне коррекции С7070 в дозе 50 мг/кг калиевой солью C7070 в дозе 10 мг/кг толщина фоторецепторного слоя, внутреннего ядерного слоя, ганглионарного слоя и нервных волокон достоверно не отличаются от соответствующих значений нормы. Заключение: В эксперименте выявлено, что субстанция калиевой соли С7070 в дозе 10 мг/кг обладает ретинопротективным действием, заключающимся в сохранении структуры ядерных слоев сетчатки и слоя фоторецепторов, уменьшении ишемических повреждений сетчатки.

Ключевые слова: калиевая соль 3-(1Н-бензимидазол-2-ил)-1,2,2триметилциклопентанкарбоновой кислоты; ишемия-реперфузия сетчатки; агонисты имидазолиновых рецепторов I, II типов
\end{abstract}

Для цитирования: Сернов ЛН, Левкова ЕА. Коррекция ишемическихреперфузионных повреждений сетчатки у крыс с использованием агонистов имидазолиновых рецепторов I, II типов. Научные результаты биомедицинских исследований. 2019;5(2):52-61. DOI: 10.18413/2658-6533-2019-5-2-0-6 


\title{
Lev N. Sernov, Elena A. Levkova \\ Correction of ischemic and reperfusion damage in the retina by using imidazoline receptors agonists of types I, II in rats
}

\author{
OOO "Pharmconsulting", \\ 19 Kirov St., Staraya Kupavna, 142450, Russia \\ Corresponding author: Elena A. Levkova (last_81@mail.ru)
}

\begin{abstract}
Background: The authors note that special literature does not make mention of drugs for targeted, specific correction of retinal ischemia. That is why the study of the possibilities of pharmacological correction of ischemic and reperfusion injuries of the retina in the experiment is urgent. The aim of the study: To increase the effectiveness of pharmacological correction of ischemic and reperfusion injuries of the retina by using types I, II agonists of imidazoline receptors. Materials and methods: Evaluation of the protective properties of imidazoline receptor agonists in a retinal ischemia-reperfusion model in Wistar rats by using C7070 substance (3- (1H-benzimidazol-2-yl) -1,2,2trimethylcyclopentanecarboxylic acid) in doses of $10 \mathrm{mg} / \mathrm{kg}$ and $50 \mathrm{mg} / \mathrm{kg}$ and potassium salt of C7070 in a dose of $10 \mathrm{mg} / \mathrm{kg}$ were performed according to the dynamics of morphometric parameters of the thickness of retinal layers. Results: On the model of retinal ischemia-reperfusion, it was shown that the potassium salt of $\mathrm{C} 7070$ has a more pronounced retinoprotective effect than C7070. With correction by C7070 in a dose of $10 \mathrm{mg} / \mathrm{kg}$, the photoreceptor layer is $10.9 \%$ (p>0.05) thicker compared with the value in the group with the pathology model and does not differ significantly from it; the inner nuclear layer is $21.6 \%$ thicker than in the group with the model $(\mathrm{p}<0.05)$; the thickness of the ganglionic layer and nerve fibers is not significantly different from the value in the group with the pathology model. With correction by C7070 in a dose of $50 \mathrm{mg} / \mathrm{kg}$ with potassium salt of $\mathrm{C} 7070$ in a dose of $10 \mathrm{mg} / \mathrm{kg}$, the thickness of the photoreceptor layer, inner nuclear layer, ganglionic layer and nerve fibers does not differ significantly from the corresponding values of the norm. Conclusion: The experiment has revealed that the substance of potassium salt of C7070 in a dose of $10 \mathrm{mg} / \mathrm{kg}$ has a retinoprotective effect, which consists in preserving the structure of the nuclear layers of the retina and the layer of photoreceptors, and reducing the ischemic damage to the retina.

Keywords: potassium salt of 3-(1H-benzimidazol-2-yl)-1,2,2trimethylcyclopentanecarboxylic acid; retinal ischemia-reperfusion; imidazoline receptor agonists types I, II
\end{abstract}

For citation: Sernov LN, Levkova EA. Correction of ischemic and reperfusion damage in the retina by using imidazoline receptors agonists of types I, II in rats. Research Results in Biomedicine. 2019;5(2):52-61. (In Russian) DOI: 10.18413/2658-6533-2019-52-0-6

Введение. Патологические изменения ретинальных сосудов ведут к формированию ретинальной ишемии, что, в свою очередь, приводит к развитию ретинопатии, слепоте и инвалидности по зрению [1]. Примерно 100 миллионов людей в мире страдают ишемическими изменениями в сетчатке $[2,3,4]$. Рост заболеваемости ги- пертонической болезнью, атеросклерозом приводят к увеличению ишемических повреждений сетчатки. Ишемия сетчатки возникает в $35 \%$ случаев у пациентов с атеросклеротическими изменениями сердечнососудистой системы, в $25 \%$ случаев - у пациентов с гипертонической болезнью $[5,6]$. Ишемия формируется на фоне нехватки 
кислорода, приводящей к угнетению метаболических процессов в тканях глаза с апоптозом нейронов сетчатки [7]. Ишемическая нейропатия является глазным симптомом различных системных заболеваний. Патология сосудистой системы глаза является одной из ведущих причин слабовидения и слепоты у различных возрастных групп населения [8].

Существует тесная взаимосвязь между поражением различных звеньев системы кровообращения и механизмом развития ишемии. В основе ишемии лежат как общие ангиоспастические заболевания, так и острая ишемия заднего отрезка глаза, проявляющаяся нарушениями кровообращения центральной артерии сетчатки, центральной вены сетчатки, нейропатии [9]. Клиническая картина характеризуется внезапным и стойким снижением визуса, дефектами в поле зрения, слепотой. Прогноз всегда серьезный, но не безнадежный. Под влиянием лечения может наступить улучшение или стабилизация процесса. Часто требуются повторные курсы лечения.

В настоящее время нет эффективного метода терапии ишемической нейропатии, несмотря на то, что она является ведущей патологией в системе заболеваний зрительного нерва и приводит к потере остроты зрения [10].

Коррекцию

ишемическихреперфузионных повреждений сетчатки возможно проводить с применением агонистов имидазолиновых рецепторов [11], поэтому актуальным явилось изучение возможностей коррекции ишемии сетчатки новым представителем лигандов имидазолиновых рецепторов I, II типа с более высокой биодоступностью - калиевой солью С 7070.

Цель исследования: повышение эффективности фармакологической коррекции ишемических-реперфузионных повреждений сетчатки с применением агонистов имидазолиновых рецепторов I, II типов.

Материалы и методы исследования. В экспериментах участвовало 50 крыс линии Wistar, самцов и самок, массой 225275 г. В каждой группе было по 10 крыс. Первая группа - интактные животные, вторая - модель ишемии-реперфузии (кон- троль), третья - с коррекцией патологии субстанцией С7070 в дозе 10 мг/кг, четвертая - с коррекцией С7070 в дозе 50 мг/кг, пятая - с коррекцией калиевой солью С7070 в дозе 10 мг/кг. Все манипуляции и операции на животных проводились в условиях общего обезболивания путем внутрибрюшинного введения раствора хлоралгидрата в дозе 300 мг/кг массы крысы.

Моделирование ишемии-реперфузии проводили путем однократного повышения внутриглазного давления (ВГД) до 110 мм.рт.ст. в течение 30 мин [5, 12, 13, 14].

В третьей группе вводили субстанцию С7070 интрагастрально через зонд однократно в дозе 10 мг/кг за 60 мин до повышения ВГД.

В четвертой группе за 60 мин до повышения ВГД вводили субстанцию С7070 интрагастрально однократно в дозе 50 мг/кг [11].

Калиевую соль С7070 в дозе 10 мг/кг вводили интрагастрально через зонд за 60 мин до ишемии.

Через 72 часа реперфузии производили полное извлечение глазного яблока с прилежащими структурами для гистологического исследования и фиксировали иммерсионным способом в $10 \%$ растворе формалина [15]. После фиксации глазное яблоко строго через центр разрезали в меридианном направлении на две части и обе половины заливали по стандартной методике в парафин. Серийные срезы 5-7 мкм толщиной изготавливали в меридианном направлении, которые окрашивали гематоксилином и эозином. Гистологическая обработка на всех этапах выполнена с использованием оборудования фирмы «Leica» (Германия). Готовые препараты для микроскопического исследования и архивирования сканировали с помощью компьютерной системы архивирования и анализа изображений "Mirax Desk". Анализ изображений выполнены с помощью программы «Pannoramic Viewer» 1.15.4.

Результаты и их обсуждение. В эксперименте с введением С7070 в дозах 10 мг/кг и 50 мг/кг, калиевой соли С7070 в дозе 10 мг/кг выявлены морфометрические изменения в толщине слоев сетчатки, которые 
свидетельствуют о различной степени коррекции повреждений при ишемииреперфузии.

Гистологическая структура сетчатки крыс линии Wistar из группы интактных животных представлена на рисунке 1.

Сетчатка представлена четко упорядоченной структурой с хорошо дифференцируемыми основными слоями, которые образованы перикарионами нейронов (ядерные и ганглионарный слои) и их отростками (сетчатые слои и слой нервных волокон). Фоторецепторный слой в норме относительно однородный, характеризуется слабо выраженным радиальным рисунком. Ядерные слои образованы плотно расположенными ядрами со средней интенсивностью базофильной окраски. Сетчатые слои и слой нервных волокон имеют мелкозернистый вид, гомогенную эозинофильную окраску. Ганглионарный слой образован среднего и крупного размера нейронами с крупными эухроматиновой структуры ядрами.

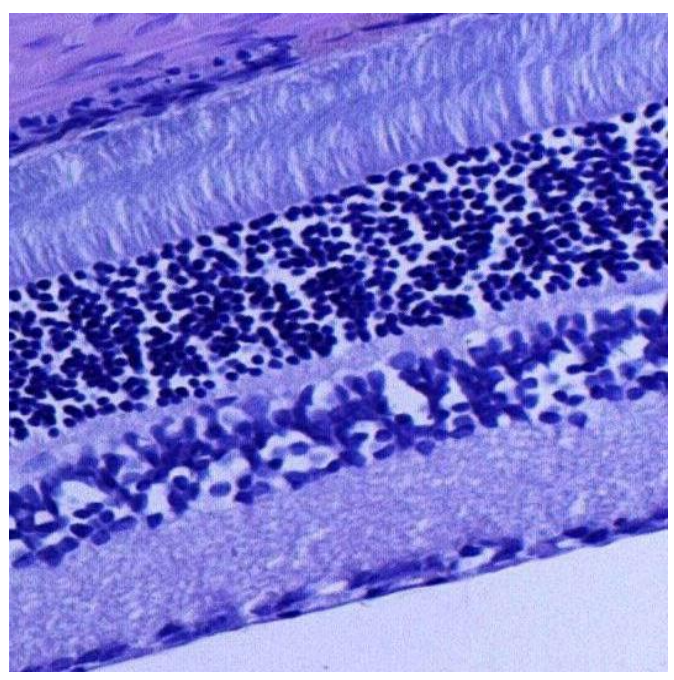

Рис. 1. Гистологическая структура сетчатки крысы интактной группы. Окр. гематоксилином и эозином. Микрофото. х200

Fig.1. Histological structure of the retina in a rat from the intact group. Stained with haema-

toxylin and eosin. Microphoto. x200

Результаты гистологического исследования подтвердили формирование ишемии через 72 ч реперфузии в сетчатке в группе с моделированием патологии (рис. 2).

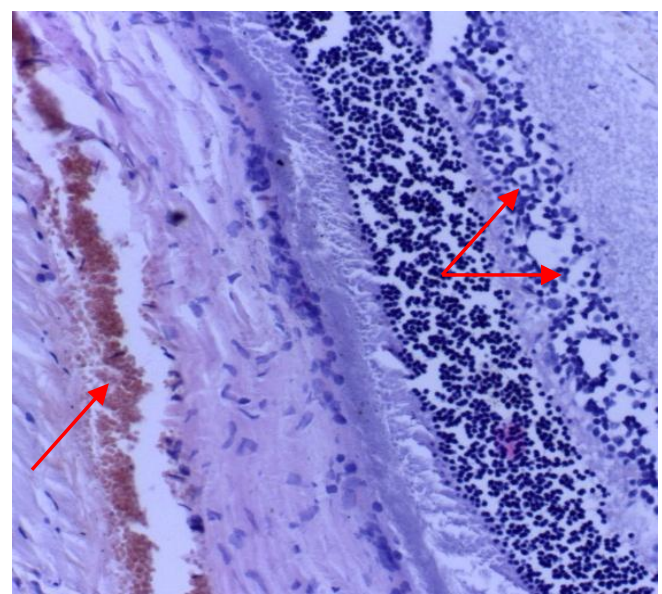

Рис. 2. Морфология сетчатки крыс с экспериментальной ретинальной ишемиейреперфузией. Выраженные дегенеративные изменения через 72 часа реперфузии. Дилатация вен и венул на уровне хориоидеи (стрелка). Структурные изменения сетчатки в виде отечных изменений и разрыхления внутреннего ядерного слоя (двойная стрел-

ка). Окр. гематоксилином и эозином. Микрофото. х200

Fig. 2. Retinal morphology of rats with experimental retinal ischemia-reperfusion. Pronounced degenerative changes after 72 hours of reperfusion. Dilation of veins and venules at the level of the choroidal (arrow). Structural retinal changes in the form of edematous changes and loosening of the inner nuclear layer (double arrow). Stained with haematoxylin and eosin. Microphoto. x200

В группе с моделью патологии у всех животных выявлены выраженные морфологические изменения нейронов. В слое фоторецепторов выявлена структурная дискомплексация. Слой терял радиальную исчерченность, создаваемую за счет компактного расположения отростков нейронов, принимал разрыхленный вид. Присутствуют признаки деструкции дендритов по типу глыбчатого распада. В ядерных слоях сетчатки наблюдались сходные изменения в виде декомпактизации расположения ядер, формирования спонгиоформных пустот.

Морфология сетчатки крыс с коррекцией ишемии-реперфузии С7070 в дозе 10 мг/кг представлена на рисунке 3 А.

Результаты гистологических исследований подтвердили наличие выраженных 
протективных свойств у С7070 в дозе 50 мг/кг на модели ишемии-реперфузии сетчатки. Наблюдаемая картина почти не

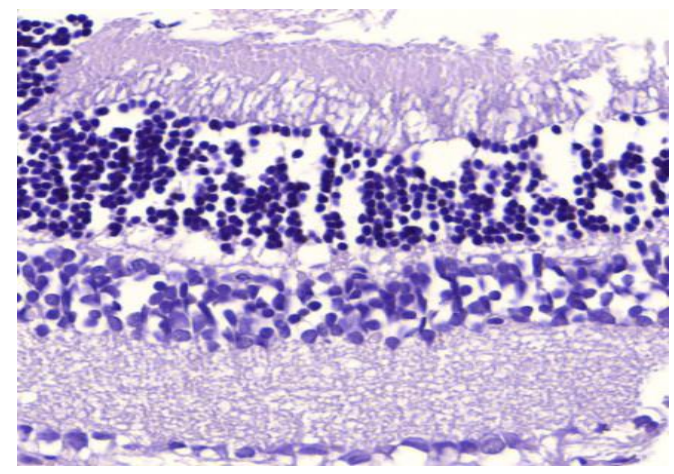

A отличается от нормы и представлена на рисунке 3 Б.

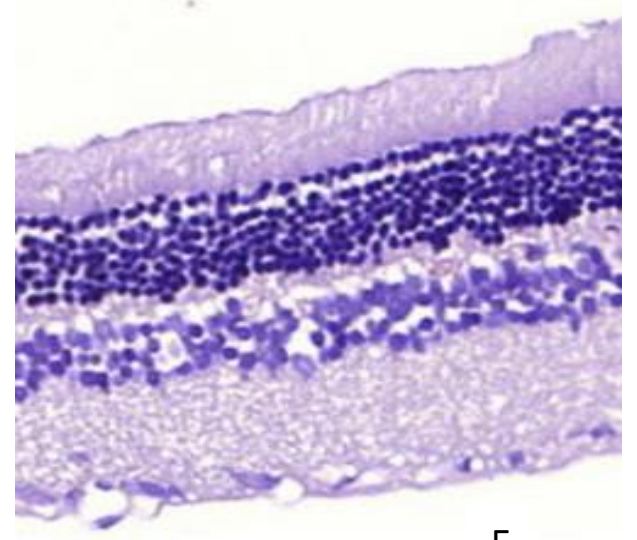

Б

Рис. 3. А - Морфология сетчатки крыс с коррекцией ретинальной ишемии-реперфузии С7070 в дозе 10 мг/кг. Выраженные отечные изменения во внутреннем ядерном и наружном ядерном слоях. Дискомплексация структуры фоторецепторного слоя. Перинейрональный отек в ганглионарном слое. Б - Морфология сетчатки крысы с коррекцией ретинальной ишемии-реперфузии С7070 в дозе 50 мг/кг. Сохранность структуры слоев. Редкие отечные изменения во внутреннем ядерном слое. Небольшой перинейрональный отек в ганглионарном слое. Окр. гематоксилином и эозином. Микрофото. х200

Fig. 3. A - Retinal morphology of rats with retinal ischemia-reperfusion correction with $\mathrm{C} 7070$ at a dose of $10 \mathrm{mg} / \mathrm{kg}$. Pronounced edematous changes in the inner nuclear and outer nuclear layers. Structure discomplexation of the photoreceptor layer. Perineural edema in the ganglionic layer. B - Retinal morphology of rats with retinal ischemia-reperfusion correction with C7070 at a dose of $50 \mathrm{mg} / \mathrm{kg}$. Preservation of the layers structure. Rare edematous changes in the inner nuclear layer. Slight perineural edema in the ganglion layer. Stained with haematoxylin and eosin. Microphoto. x200

В группе с введением калиевой соли С7070 в меньшей степени были выражены повреждения в фоторецепторном слое и проявлялись в виде умеренной гомогенизации за счет более плотного расположения дендритов фоторецепторных нейронов. Незначительные изменения были в наружном ядерном слое: во-первых, качественные свето-микроскопические признаки нейрональных потерь в виде пикноморфных изменений нейронов, разрежения слоя с расширением межклеточных пространств (рис. 4), во-вторых, уменьшение плотности клеточного состава сопровождалось изменениями дистрофического и отечного типов в виде спонгиоза и вакуолизации межклеточных пространств, количественным отражением чего служит увеличение толщины слоя (рис. 5). При этом наружный сетчатый и внутренний ядерный слои оказались наименее измененными.

Сравнительная картина структуры сетчатки в группах с введением С7070 в дозе 50 мг/кг и калиевой соли C7070 в дозе 10 мг/кг представлена на рисунке 5 .

Результаты морфометрии слоев сетчатки в экспериментальных группах представлены в таблице. 


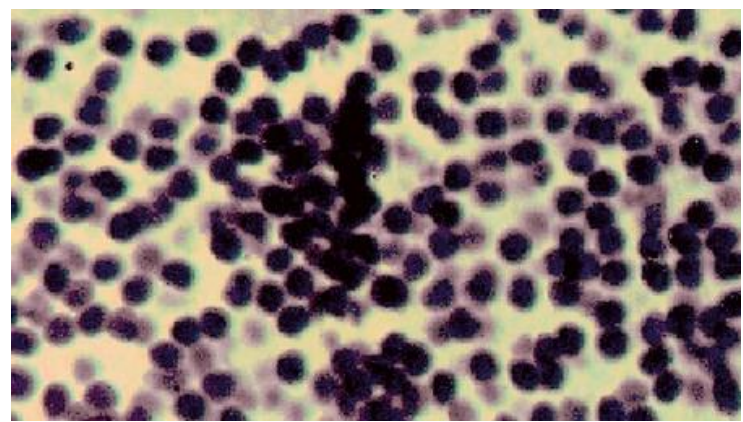

Рис .4. Изменения в наружном ядерном слое в группе с введением калиевой соли С7070 (умеренные пикноморфные изменения нейронов, расширение межклеточных пространств).

Окр. гематоксилином и эозином. Микрофото. х400

Fig. 4. Changes in the outer nuclear layer in the group with the injection of potassium salt C7070 (moderate pycnomorphic changes of neurons, expansion of intercellular spaces).

Stained with haematoxylin and eosin. Microphoto. $x 400$
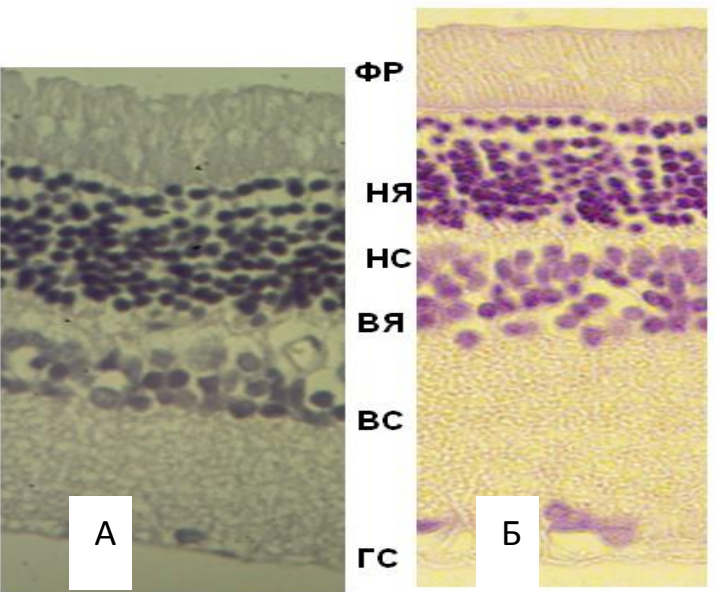

Примечания: ФР - слой фоторецепторов; НЯ - наружный ядерный слой; НС - наружный сетчатый слой; ВЯ - внутренний ядерный слой; ВС - внутренний сетчатый слой; ГС - ганглионарный слой

Notes: ФР - a layer of photoreceptors; НЯ - the outer nuclear layer; HC - the outer mesh layer; ВЯ inner nuclear layer; $\mathrm{BC}$ - the inner mesh layer; $\Gamma \mathrm{C}$ - ganglion layer

Рис.5. Сравнительная картина структуры сетчатки крыс при коррекции ретинальной ишемииреперфузии субстанцией С7070 в дозе 50 мг/кг (А) и калиевой солью С7070 в дозе 10 мг/кг (Б).

Окр. гематоксилином и эозином. Микрофото. х200

Fig. 5. A comparative picture of the retinal structure of rats in the correction of retinal ischemiareperfusion with substance $\mathrm{C} 7070$ at a dose of $50 \mathrm{mg} / \mathrm{kg}$ (A) and potassium salt C7070 at a dose of $10 \mathrm{mg} / \mathrm{kg}$ (B). Stained with haematoxylin and eosin. Microphoto. x200 
Таблища 1

Влияние С7070 в дозах 10 мг/кг, 50мг/кг, калиевой соли С7070 в дозе 10 мг/кг на толщину слоев сетчатки через 72 ч реперфузии при коррекции ретинальной ишемии-реперфузии $(\mathrm{M} \pm \mathbf{m} ; \mathbf{n}=\mathbf{1 0}), \mathbf{м к м}$

Table 1

Effect of C7070 at doses of $10 \mathrm{mg} / \mathrm{kg}, 50 \mathrm{mg} / \mathrm{kg}$, potassium salt C7070 at a dose of $10 \mathrm{mg} / \mathrm{kg}$ on the thickness of retinal layers after 72 hours of reperfusion in the correction of retinal ischemia-reperfusion ( $M \pm m ; n=10)$, microns

\begin{tabular}{|c|l|c|c|c|}
\hline \multirow{2}{*}{$\begin{array}{c}\text { № } \\
\text { п/п }\end{array}$} & \multicolumn{1}{|c|}{ Экспериментальные группы } & $\begin{array}{c}\text { Фоторецеп- } \\
\text { торный }\end{array}$ & $\begin{array}{c}\text { Внутренний } \\
\text { ядерный }\end{array}$ & $\begin{array}{c}\text { Ганглионарный } \\
\text { и нервных воло- } \\
\text { кон }\end{array}$ \\
\hline 1 & Интактные & $52,6 \pm 1,7$ & $26,4 \pm 1,3$ & $17,8 \pm 1,0$ \\
\hline 2 & Ишемия-реперфузия сетчатки & $36,6 \pm 0,7^{*}$ & $20,4 \pm 0,8^{*}$ & $21,3 \pm 0,9^{*}$ \\
\hline 3 & Коррекция С7070,10 мг/кг & $40,6 \pm 1,5^{*}$ & $24,8 \pm 1,4^{\mathrm{y}}$ & $19,6 \pm 1,3^{*}$ \\
\hline 4 & Коррекция С7070, 50 мг/кг & $50,1 \pm 1,2^{\mathrm{y}}$ & $25,4 \pm 1,4^{\mathrm{y}}$ & $18,2 \pm 1,3^{\mathrm{y}}$ \\
\hline 5 & $\begin{array}{l}\text { Коррекция калиевой солью } \\
\text { С7070, 10 мг/кг }\end{array}$ & $52,3 \pm 1,5^{\mathrm{y}}$ & $26,0 \pm 1,2^{\mathrm{y}}$ & $18,7 \pm 1,4^{\mathrm{y}}$ \\
\hline
\end{tabular}

Примечание: * - p<0,05 в сравнении с интактными; у $-\mathrm{p}<0,05$ в сравнении с ишемиейреперфузией сетчатки.

Note: ${ }^{*}-\mathrm{p}<0.05$ compared to intact rats; $\mathrm{y}-\mathrm{p}<0.05$ compared to retinal ischemia-reperfusion.

При моделировании патологии толщина фоторецепторного слоя уменьшается на $30,4 \%$, внутреннего ядерного - на 22,7\%, ганглионарного и нервных волокон - увеличивается на 19,7\% по сравнению с нормой $(p<0,05)$. Увеличение толщины нервных волокон ганглионарного слоя и наблюдается за счет формирования отека.

На фоне коррекции С7070 в дозе 10 мг/кг толщина фоторецепторного слоя больше на $10,9 \%(\mathrm{p}>0,05)$ по сравнению со значением в группе с патологией и достоверно не отличается от него; толщина внутреннего ядерного слоя на $21,6 \%$ больше, чем в группе с патологией $(\mathrm{p}<0,05)$; толщина ганглионарного слоя и нервных волокон достоверно не отличается от значения в группе с моделью патологии.

На фоне коррекции С7070 в дозе 50 мг/кг и калиевой солью С7070 толщина фоторецепторного слоя, внутреннего ядерного слоя, ганглионарного слоя и нервных волокон достоверно не отличаются от соответствующих значений нормы.

Таким образом, при гистологическом и морфометрическом исследовании сетчаток крыс в экспериментальных группах с коррекцией ретинальной ишемии-реперфузии выявлено наиболее выраженное протективное действие у калиевой соли С7070 в дозе 10 мг/кг и С7070 в дозе 50 мг/кг, заключающееся в сохранении структуры ядерных слоев и слоя фоторецепторов, уменьшении ишемических повреждений в сетчатке, которые отмечались в группе с моделью ишемии-реперфузии.

Результаты исследования позволяют обосновать новые перспективные направления поиска и создания эффективных лекарственных препаратов для специфической коррекции ишемических повреждений сетчатки. В перспективе применения агонистов имидазолиновых рецепторов I, II типов можно отметить их терапевтический потенциал в качестве нейропротектора.

Имидазолиновые рецепторы II типа обнаружены в головном мозге, и лиганды этих рецепторов могут проявлять нейропротекторные эффекты [16, 17]. Имидазолиновые рецепторы II типа - новая биомишень для коррекции неврологических патологий [18]. Активация имидазолиновых рецепторов приводит к ингибированию $\mathrm{Na}+/ \mathrm{H}+$ ионообменных каналов [19]. Опубликованы экспериментальные данные о нейропротекторной активности ингибиторов $\mathrm{Na}+/ \mathrm{H}+$ 
ионообменных каналов 1 изоформы NHE-1. NHE-1 широко экспрессируются во всех изученных типах нейронов, эпителиальных клетках сосудистой оболочки, глиальных клетках [20].

В клинических рекомендациях по лечению ишемической нейропатии не указаны средства для направленной, специфической коррекции ишемических повреждений сетчатки [21]. Коррекция ишемических повреждений осуществляется за счет раскрытия резервных капилляров, расширения сосудов, развития коллатерального кровообращения [22]. В связи вышеизложенным, является перспективным изучение возможностей фармакологической коррекции, а именно нейропротекции, морфофункциональных повреждений сетчатки на моделях in vitro и in vivo.

Заключение. В эксперименте выявлено, что калиевая соль С7070 в дозе 10 мг/кг обладает ретинопротективным действием на модели ишемии-реперфузии сетчатки, заключающимся в сохранении структуры ядерных слоев сетчатки и слоя фоторецепторов, уменьшении ишемических повреждений сетчатки.

В отнотении данной статьи не было зарегистрировано конфликта интересов.

\section{Список литературы}

1. Angiographic signatures of the predominant form of familial transthyretin amyloidosis (Val30Met mutation) / A. Rousseau [et al.] // Am. J. Ophthalmol. 2018. Vol. 192. P. 169-177. DOI: https://doi.org/10.1016/j.ajo.2018.05.023

2. Худяков А.Ю., Сорокин Е.Л. Сравнительный анализ результатов хирургического лечения тромбоза ветви центральной вены сетчатки в зависимости от срока проведения операции // Современные технологии в офтальмологии. 2014. N 2. C. 67-69.

3. Animal models for retinal diseases / ed. by I.H. Pang, A.F. Clark // Humana Press, 2010. DOI: 10.1007/978-1-60761-541-5

4. Retinal ischemia: mechanisms of damage and potential therapeutic strategies / N.N. Osborne [et al.] // Prog. Retin. Eye Res. 2004. Vol. 23(1). P. 91-147.

DOI: https://doi.org/10.1016/j.preteyeres.2003.12.001

5. Pharmacological correction of retinal ischemia/reperfusion by minoxidil / A.A. Peresyp- kina [et al.] // Serbian Archives of Medicine. 2018. Vol. $146 . \quad$ P. 530-533. DOI: https://doi.org/10.2298/SARH170814006P

6. Кацнельсон Л.А., Форофонова Т.И., Бунин А.Я. Сосудистые заболевания глаз. Москва: Медицина. 1990. 268 с.

7. Hayreh S.S. Ischemic optic neuropathies where are we now? // Graefes Arch. Clin. Exp. Ophthalmol. 2013. Vol. 251(8). P. 1873-1884. DOI: https://doi.org/10.1007/s00417-013-2399-z

8. Камилов Х.М. Состояние общей и регионарной гемодинамики при глазном ишемическом синдроме // Вестник Тамбовского университета. Сер. Естественные и технические науки. 2015. Т. 20, N 3. С. 596-599.

9. Елисеева Т.О. Методы лечения ишемических состояний зрительного нерва и сетчатки // Русский медицинский журнал. Сер. Клиническая офтальмология. 2002. N 3. С. 106-111.

10.Эффекты фармакологического прекондиционирования никорандилом и миноксидилом в хирургии / И.М. Колесник [и др.] // Кубанский научный медицинский вестник. 2012. N 3(132). C. 86-88.

11.Коррекция экспериментальной ишемической нейропатии зрительного нерва агонистом имидазолиновых рецепторов типов I и II / А.А. Пересыпкина [и др.] // Экспериментальная и клиническая фармакология. 2018. Т. 81, N 4. C. 12-17. DOI: https://doi.org/10.30906/0869-20922018-81-4-12-17

12.Электрофизиологические и гистоморфометрические изменения в сетчатке крыс при фармакологическом прекондиционировании эритропоэтином, никорандилом на модели ишемии-реперфузии глаза / А.А. Пересыпкина [и др.] // Научные ведомости БелГУ. Сер. Медицина. Фармация. 2014. Вып. 26/1, N 11(182). C. 113-117.

13.Analysis of the protective properties of erythropoetin and nicorandil on the basis of the model of the retina ischemia/reperfusion / A.S. Shabelnikova [et al.] // Research journal of pharmaceutical, biological and chemical sciences. 2014. Vol. 5(6). P. 1335-1339.

14.Pharmacological preconditioning by recombinant erythropoietin - a new way of treatment of retinal ischemia/reperfusion / A.S. Shabelnikova [et al.] // International journal of pharmacy \& technology. 2016. Vol. 8(4). P. 26889-26896.

15.Протективное действие эритропоэтина при моделировании ишемии-реперфузии сетчатки / А.С. Шабельникова [и др.] // Научные ведомости БелГУ. Сер. Медицина. Фармация. 2014. Вып. 26/1, N 11(182). С. 109-112. 
16.Head G.A., Mayorov D.N. Imidazoline receptors, novel agents and therapeutic potential // Cardiovasc. Hematol. Agents Med. Chem. 2006. Vol. 4(1) P. 17-32. DOI: https://doi.org/10.2174/187152506775268758

17. Neuroprotective effects of a structurally new family of high affinity Imidazoline $I_{2}$ receptor ligands / S. Abás [et al.] // ACS Chem. Neurosci. 2017. Vol. 8(4). P. 737-742. DOI: https://doi.org/10.1021/acschemneuro.6b00426

18.Li J.X. Imidazoline $\mathrm{I}_{2}$ receptors: an update // Pharmacol. Ther. 2017. N 178. P. 48-56. DOI: https://doi.org/10.1016/j.pharmthera.2017.03.009

19.Ernsberger $\mathrm{P}$. The $\mathrm{I}_{1}$-imidazoline receptor and its cellular signaling pathways // Ann. NY Acad. Sci. 1999. N 881. P. 35-53. DOI: https://doi.org/10.1111/j.1749-6632.1999.tb09339.x

20.Нейропротекторные свойства нового ингибитора $\mathrm{Na}^{+} / \mathrm{H}^{+}$-обменника соединения РУ1355 на модели фокальной ишемии у крыс / А.А. Спасов [и др.] // Экспериментальная и клиническая фармакология. 2016. Т. 79, N 4. С. 3-7. DOI: https://doi.org/10.30906/0869-2092-2016-794-3-7

21.Способ лечения и профилактики глазных болезней, связанных с ишемией тканей глаз: пат. 2268722 Рос. Федерация: МПК А61K31/401, А61P27/00 / авт., заявители и патентообладатели О. А. Кост, Н. Б. Чеснокова, П. В. Макаров [и др.]. № 2004105876/14; заявл. 01.03.2004; опубл. 27.01.2006. Бюл. № $3.12 \mathrm{c}$.

22.Елисеева Т.О. Применение вазоактивных препаратов в лечении ишемических заболеваний сетчатки // Русский медицинский журнал. Сер. Офтальмология, педиатрия. 2000. N 1. C. 16-18.

\section{References}

1. Rousseau A, Terrada C, Touhami S, et al. Angiographic signatures of the predominant form of familial transthyretin amyloidosis (Val30Met mutation). Am. J. Ophthalmol. 2018;192:169-177. DOI: https://doi.org/10.1016/j.ajo.2018.05.023

2. Khudyakov AYu, Sorokin EL. [Comparative analysis of the results of surgical treatment of thrombosis of branches of the central retinal vein, depending on the duration of the operation]. Modern technologies in ophthalmology. 2014;2:67-69. Russian.

3. Pang IH, Clark AF, editors. Animal models for retinal diseases. Humana Press; 2010. DOI: 10.1007/978-1-60761-541-5

4. Osborne NN, Casson RJ, Wood JP, et al. Retinal ischemia: mechanisms of damage and potential therapeutic strategies. Prog. Retin. Eye Res.
2004;23(1):91-147.

DOI:

https://doi.org/10.1016/j.preteyeres.2003.12.001

5. Peresypkina AA, Gubareva VO, Levkova EA, et al. Pharmacological correction of retinal ischemia/reperfusion by minoxidil. Serbian Archives of Medicine. 2018;146:530-533. DOI: https://doi.org/10.2298/SARH170814006P

6. Katsnelson LA, Farafonova TI, Bunin AYa. [Vascular diseases of the eyes]. Moscow: Medicina; 1990. Russian.

7. Hayreh SS. Ischemic optic neuropathies where are we now? Graefes Arch. Clin. Exp. Ophthalmol. 2013;251(8):1873-1884. DOI: https://doi.org/10.1007/s00417-013-2399-z

8. Kamilov HM. [State of general and regional hemodynamics in ocular ischemic syndrome]. Bulletin of Tambov University. Ser. Natural and Technical Sciences. 2015;20(3):596-599. Russian.

9. Eliseeva TO. [Methods of treatment of ischemic states of the optic nerve and retina]. Russian medical journal. Ser. Clinical ophthalmology. 2002;3:106-111. Russian.

10.Kolesnik IM, Pokrovskiy MV, Lazarenko VA, et al. [Effects of pharmacological preconditioning by nicorandil and Minoxidil in surgery]. Kuban state medical journal. 2012;3(132):86-88. Russian.
11.Peresypkina
AA, Pokrovskii

MV, Dolzhikov AA, et al. [Correction of experimental ischemic neuropathy of the optic nerve by imidazoline receptor type I and II]. Clinical pharmacology. 2018;81(4):12-17. Russian. DOI: https://doi.org/10.30906/0869-2092-2018-814-12-17

12.Peresypkina AA, Pokrovskiy MV, Shabelnikova AS, et al. [Electrophysiological and histomorphometric changes in the retina of rats under pharmacological preconditioning erythropoietin, nicorandil on the model of ischemia-reperfusion eyes]. Scientific statement BSU. Ser. Medicine. Pharmacy. 2014;26/1(11(182)):113-117. Russian.

13. Shabelnikova AS, Peresypkina AA, Pokrovskiy MV, et al. Analysis of the protective properties of erythropoetin and nicorandil on the basis of the model of the retina ischemia/reperfusion. Research journal of pharmaceutical, biological and chemical sciences. 2014;5(6):1335-1339.

14. Shabelnikova AS, Peresypkina AA, Pokrovskii MV, et al. Pharmacological preconditioning by recombinant erythropoietin - a new way of treatment of retinal ischemia/reperfusion. International journal of pharmacy \& technology. 2016;8(4):26889-26896. 
15. Shabelnikova AS, Kashuba AS, Peresypkina AA, et al. [Protective effect of erythropoietin in modeling retinal ischemia-reperfusion]. Scientific Bulletin of BSU. Ser. Medicine. Pharmacy. 2014;26/1(11(182)):109-112. Russian.

16. Head GA, Mayorov DN. Imidazoline receptors, novel agents and therapeutic potential. Cardiovasc. Hematol. Agents Med. Chem. 2006;4(1):17-32. https://doi.org/10.2174/187152506775268758

17.. Abás S, Erdozain AM, Keller B, et al. Neuroprotective effects of a structurally new family of high affinity Imidazoline $\mathrm{I}_{2}$ receptor ligands. ACS Chem. Neurosci. 2017;8(4):737-742. DOI: https://doi.org/10.1021/acschemneuro.6b00426

18.Li JX. Imidazoline $\mathrm{I}_{2}$ receptors: an update. Pharmacol. Ther. 2017;178:48-56. DOI: https://doi.org/10.1016/j.pharmthera.2017.03.009

19.Ernsberger $\mathrm{P}$. The $\mathrm{I}_{1}$-imidazoline receptor and its cellular signaling pathways. Ann. NY Acad. Sci. 1999;881:35-53.

DOI: https://doi.org/10.1111/j.1749-6632.1999.tb09339.x

20.Spasov AA, Muravyeva VY, Gurov NA, et al. [Neuroprotective properties of a new inhibitor of the $\mathrm{Na}^{+} / \mathrm{H}^{+}$-exchanger connection RU-1355 on the model of focal ischemia in rats]. Experimental and clinical pharmacology. 2016;79(4):3-7. Russian. DOI: https://doi.org/10.30906/0869-20922016-79-4-3-7

21.[Method of treatment and prevention of eye diseases associated with eye tissue ischemia]:
Pat. 2268722 Grew. Federation: IPC A61K31 / 401, A61P 27/00 / auth., applicants and patent holders O.A. Kost, N. Chesnokova, p. V.Makarov [et al.]. N 2004105876/14 ; Appl. 01.03.2004; publ. 27.01.2006, Byul. N 3. 12 p. Russian.

22.Eliseeva TO. [Application of vasoactive drugs in the treatment of ischemic retinal diseases]. Russian medical journal. Ser. Ophthalmology, Pediatrics. 2000;1:16-18. Russian.

\section{Информация об авторах}

Лев Николаевич Сернов, заслуженный деятель науки РФ, доктор медицинских наук, профессор, генеральный директор, ООО «Фармконсалтинг», E-mail: sernov_ln@mail.ru.

Елена Александровна Левкова, научный сотрудник, ООО «Фармконсалтинг», E-mail: last_81@mail.ru, ORCID: 0000-0002-7633-4678.

\section{Information about the authors}

Lev N. Sernov, Honored Worker of Science of RF, Doctor of Medical Sciences, Professor, Director General, OOO "Pharmconsulting", E-mail: sernov_ln@mail.ru.

Elena A. Levkova, Researcher, "Pharmconsulting", E-mail: last_81@mail.ru, ORCID: 0000-00027633-4678.

Статья поступила в редакцию 4 октября 2018 г. Receipt date 2018 October 4.

Статья принята к публикации 26 февраля 2019 г. Accepted for publication 2019 February 26. 